\title{
A slow mode wave as a possible source of Pi 2 and associated particle precipitation: a case study
}

\author{
O. Saka ${ }^{1,2}$, O. Watanabe ${ }^{2}$, K. Okada ${ }^{2}$, and D. N. Baker ${ }^{3}$ \\ ${ }^{1}$ Department of Physics, Kurume National College of Technology, Kurume, Japan \\ E-mail: saka@ges.kurume-nct.ac.jp \\ ${ }^{2}$ Department of Earth and Planetary Sciences, Kyushu University, Fukuoka, Japan \\ ${ }^{3}$ Laboratory for Atmospheric and Space Physics, University of Colorado, Boulder, USA
}

Received: 24 November 1997 / Revised: 7 September 1998 / Accepted: 28 October 1998

\begin{abstract}
An intensification of auroral luminosity referred to as an auroral break-up often accompanies the onset of geomagnetic pulsation (Pi 2) at the dip-equator. One such auroral break-up occurred at 2239 UT on 16 June, 1986, being accompanied by weak substorm activity $(\mathrm{AE} \sim 50 \mathrm{nT})$ which was recorded in all-sky image of Syowa Station, Antarctica $\left(66.2^{\circ} \mathrm{S}, 71.8^{\circ} \mathrm{E}\right.$ in geomagnetic coordinates). The associated $\mathrm{Pi} 2$ magnetic pulsation was detected by a fluxgate magnetometer in the afternoon sector at the dip-equator (Huancayo, Peru; $1.44^{\circ} \mathrm{N}, 355.9^{\circ}$ in geomagnetic coordinates; $12.1^{\circ} \mathrm{S}, 75.2^{\circ} \mathrm{W}$ in geographic coordinates; $L=1.00$ ). In spite of the large separation of the two stations in longitude and latitude, the auroral break-up and subsequent luminosity modulation were seen to be correlated with the wave form of the ground Pi 2 pulsation. This occurred in such a way that the luminosity maximum was seen to occur at the phase of maximum amplitudes of $\mathrm{Pi} 2$ wave form. We argue that the observed correlation could be interpreted as indicating a $\mathrm{Pi}$ 2modulation of a field-aligned acceleration of the low energy electrons that may occur near the equator of the midnight magnetosphere.
\end{abstract}

Key words. Magnetospheric physics (auroral phenomena; energetic particles, precipitating; MHD waves and instabilities)

\section{Introduction}

Magnetospheric substorms cause many kinds of disturbances in the ionosphere and the magnetosphere. Auroral substorms, particle injections and ULF mag-

Correspondence to: O. Saka netic pulsations are all among the observable manifestations of the magnetospheric substorm, and numerous investigations about these manifestations have been carried out over the last several decades. An auroral substorm, in particular, is generally recognized as the ionospheric projection of a magnetospheric substorm. The global morphology of luminosity during an auroral substorm was first described by Akasofu (1964) based on a large number of observations made by all-sky cameras. Magnetic pulsations associated with substorm expansion onsets have been widely investigated in 1960s and 1970s (see Saito, 1969; Jacobs, 1970). Because of their close correlation of the occurrence with substorm expansion onset, most prior pulsation studies have been carried out by use of the data from high latitude stations. Recently, magnetometer observations at the dip-equator have been utilized as ground diagnostics of magnetospheric plasma dynamics. In these studies, signals recorded at the dip-equator were found to be sensitive to the change of plasma pressure in the inner magnetosphere [Saka et al., 1996a, b, c 1997, 1998a, b, c].

The behavior of low energy particles contributing to the plasma pressure in the range of $100 \mathrm{eV}-100 \mathrm{keV}$ have been widely examined in the geosynchronous altitudes. Among these studies, electron fluxes were reported to respond differently in different energy ranges during the auroral break-up in such a way that fluxes in lower energy ranges dropped out, whereas the higher energy fluxes were enhanced (Shepherd et al., 1980). A similar response was seen in electron flux modulations by Pi 2 magnetic pulsations which appeared during particle injections at geosynchronous orbit (Arnoldy, 1986). These energy-dependent responses of the particles observed are an intriguing issue of plasma dynamics associated with the auroral break-up and magnetospheric particle injections.

In this report, a correspondence between $\mathrm{Pi} 2$ magnetic pulsations as observed at the dip-equator and break-up signatures of the aurora in all-sky images at the high-latitude ground station, Syowa Station in 
Antarctica will be investigated with high time accuracy. These ground observations suggest that the energydependent responses as outlined above may occur in the midnight magnetosphere.

\section{Observation}

An auroral break-up was observed in a Syowa all-sky image at 2239 UT on June 16, 1986 (LT UT). The event was accompanied by a weak substorm expansion onset wherein the AE index increased by $\sim 50 \mathrm{nT}$, as well as by the onset of a magnetic pulsation ( $\mathrm{Pi}$ 2) recorded by the ground station at the dip-equator (Huancayo, LT $=$ UT-5). The proton and electron flux variations at geosynchronous altitudes and ground magnetometer data are presented in Fig. 1. In the dawn sector, the lower energy (E1-E4; 30-140 keV) electron detector onboard geosynchronous satellite 1984-037 at 0313 LT detected an increase of the flux at 2243 UT with later velocity dispersion. In the premidnight sector (2011 $\mathrm{LT})$, the lower energy $(\mathrm{P} 1 ; 95-110 \mathrm{keV})$ proton detector

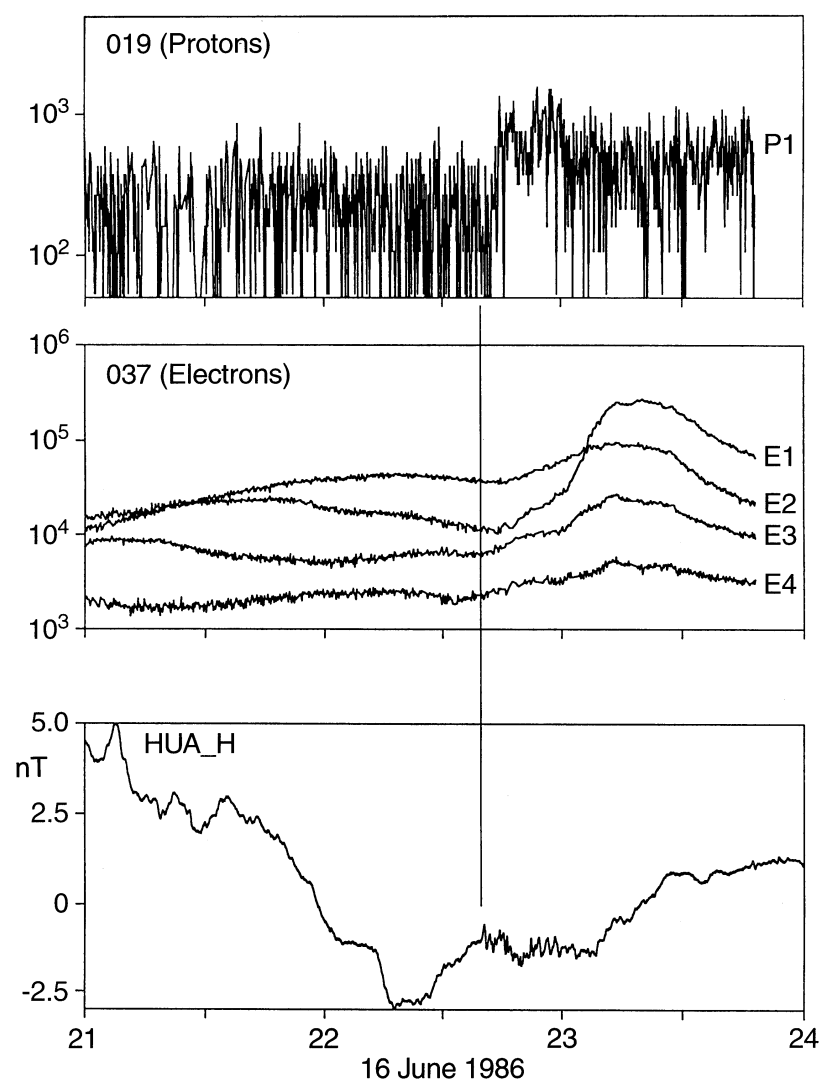

Fig. 1. (Upper two panels) proton $(95-110 \mathrm{keV})$ and electron $(30$ $140 \mathrm{keV}$ ) differential flux variation from geosynchronous satellites 1982-019 and 1984-037 in the pre-midnight and post-midnight sectors. (Bottom panel) ground magnetometer data from Huancayo (dipequator, $75^{\circ} \mathrm{W}$ ). The LT of the ground station, Huancayo is UT-5. The onset of the ground pulsation is indicated by vertical bar. Only lowest energy channel ( $\mathrm{P} 1 ; 95-110 \mathrm{keV})$ is plotted for protons, as no flux enhancement was seen to occur in the higher energy channels. For electron energy channels: E1; 30-45 keV, E2; 45-65 keV, E3; $65-$ $95 \mathrm{keV}, \mathrm{E} 4 ; 95-140 \mathrm{keV}$ onboard S/C1982-019 detected a sharp onset of the flux enhancement almost simultaneously (2.6 min delay) with the break-up onset. A mapping of the Syowa break-up to the equator in nightside magnetosphere using the Tsyganenko (1991) model indicated a breakup location at $L=8 \sim 10$ for the $2300 \mathrm{LT}$ sector. Electrons with energies lower than $10 \mathrm{keV}$ are considered to be a source of the auroral break-up (e.g., Burch, 1991). Meanwhile, we could assume that the particles with energies above $30 \mathrm{keV}$ were entrained at the breakup time (2239 UT) on the magnetic shell at such a break-up location and later executed curvature/gradient drift toward the dayside. Based on that assumption, we would estimate an expected arrival time of the particles at the satellite detectors which is consistent with the inference that the particles originated from the break-up activity (e.g., Saka et al., 1996c). In addition, taking account of the duration of the auroral precipitation in the Syowa field-of-view (FOV) (20 min) to be comparable to those of the formation of electron $(20 \mathrm{~min})$ and proton $(10 \mathrm{~min})$ flux enhancements in the downstream geosynchronous orbit, we can assume that the particle injections, though only higher energy portions were detected by the downstream satellites, were associated with the auroral break-up as recorded in the all-sky image. We describe the correspondence in detail between all-sky image and magnetometer data at the dipequator.

The Syowa FOV covers the magnetic meridian ranging from $-60.0^{\circ}$ to $-72.0^{\circ}$ in geomagnetic latitudes, and from $66.0^{\circ}$ to $80.0^{\circ}$ in geomagnetic longitudes. The auroral activities were seen to occur in the southern half of the FOV as is demonstrated in the meridian scan of these auroral break-up region in the top panel of Fig. 2. To investigate the evolution of the auroral activity along a geomagnetic longitude, the eastwest scan across $-68.5^{\circ}$ (second panel), and across $-68.0^{\circ}$ (third panel) near the equatorward boundary where the activity was higher are shown (hereafter, referred to as the dynamic display). At the fourth panel, the $H$ component at the dip-equator is shown with the same time scale as the auroral display. First, we emphasize that auroral structure begins with a westward traveling surge (WTS) and the westward drift continues throughout the event (see second and third panels). The drift velocity is estimated to be in a range of $2 \sim 4 \mathrm{~km} / \mathrm{s}$ which is compatible with the $\mathrm{E} \times \mathrm{B}$ drift of the convection electric fields (Nakamura and Oguti, 1987). Secondly, the auroral break-up begins with a sharp increase of the auroral luminosity that can be inferred from the dynamic display. The sharp increase is accompanied by a sharp increase of the $H$ component of the ground signal. This association will be discussed in detail later. The ground signal indicates an onset of the magnetic pulsations that contains an irregular wave from in a higher frequency band $(15 \sim 20 \mathrm{mHz})$ being superimposed on the lower band in the range of $10 \mathrm{mHz}(\sim 2 \mathrm{~min})$ as is shown in the dynamic power spectra (by the FFT technique employing 256 points of 3 -s fluxgate magnetometer data) in Fig. 3. Such wave characteristics including higher frequency bands were 
seen to occur even in the morning sector of Kuju $\left(L=1.2 ; 25.9^{\circ} \mathrm{N}, 202.4^{\circ} \mathrm{E}\right.$ in geomagnetic coordinates, $\mathrm{LT}=\mathrm{UT}+9)$ as demonstrated by the dynamic power spectra. The event appeared over the wider range of longitudes on the ground. Such an occurrence and the injection-associated signatures may classify the event as a Pi 2 pulsation.

In the dynamic display, the E-W bin was sampled at every $6 \mathrm{~s}$. The luminosity in each bin was integrated along the longitude $\left(-68.5^{\circ}\right)$ to demonstrate the total luminosity modulation with time. In the last two panels, such integrated luminosity variations are presented. Particularly in the bottom panel, the base line was subtracted to emphasize the modulations in the latter part of the activities. A possible correspondence between the luminosity variation and the ground $\mathrm{Pi} 2$ wave form is suggested by vertical bars in Fig. 2. The correspondence indicates that the auroral luminosity was in the enhanced level during the peak amplitudes of the ground pulsation that occurred at 2240.5, 2242.0,
$2252.5,2254.6,2256.8,2258.8,2300.0$, and $2302.6 \mathrm{UT}$ as are shown by vertical bars. To demonstrate the correlation for the first peak, the all-sky image sampled at $9 \mathrm{~s}$ interval are shown in Fig. 4 (2239:00 UT-2241:15 UT). The auroral arc appeared at the low latitude edge of the FOV at 2239:00 UT and it increased the luminosity gradually thereafter forming the maximum brightening at 2240:12-2240:21 UT. This time interval is shown by the horizontal bar in the enlarged portion of the ground Pi 2 wave form in the second panel of Fig. 3. In addition, the correlation for the second Pi 2 peak with respect to the auroral luminosity is examined in Fig. 5 (2240:51 UT-2243:06 UT). For this case, the auroral brightening that appeared at the upper-left corner (eastern edge of FOV) increased the luminosity and attained the maximum level during 2241:18-2241:45 UT. This time interval is shown again in the second panel of Fig. 3. There appeared to be no clear correspondence between the auroral luminosity and the $\mathrm{Pi} 2$ wave form until the sharp Pi 2 peak occurred at 2252

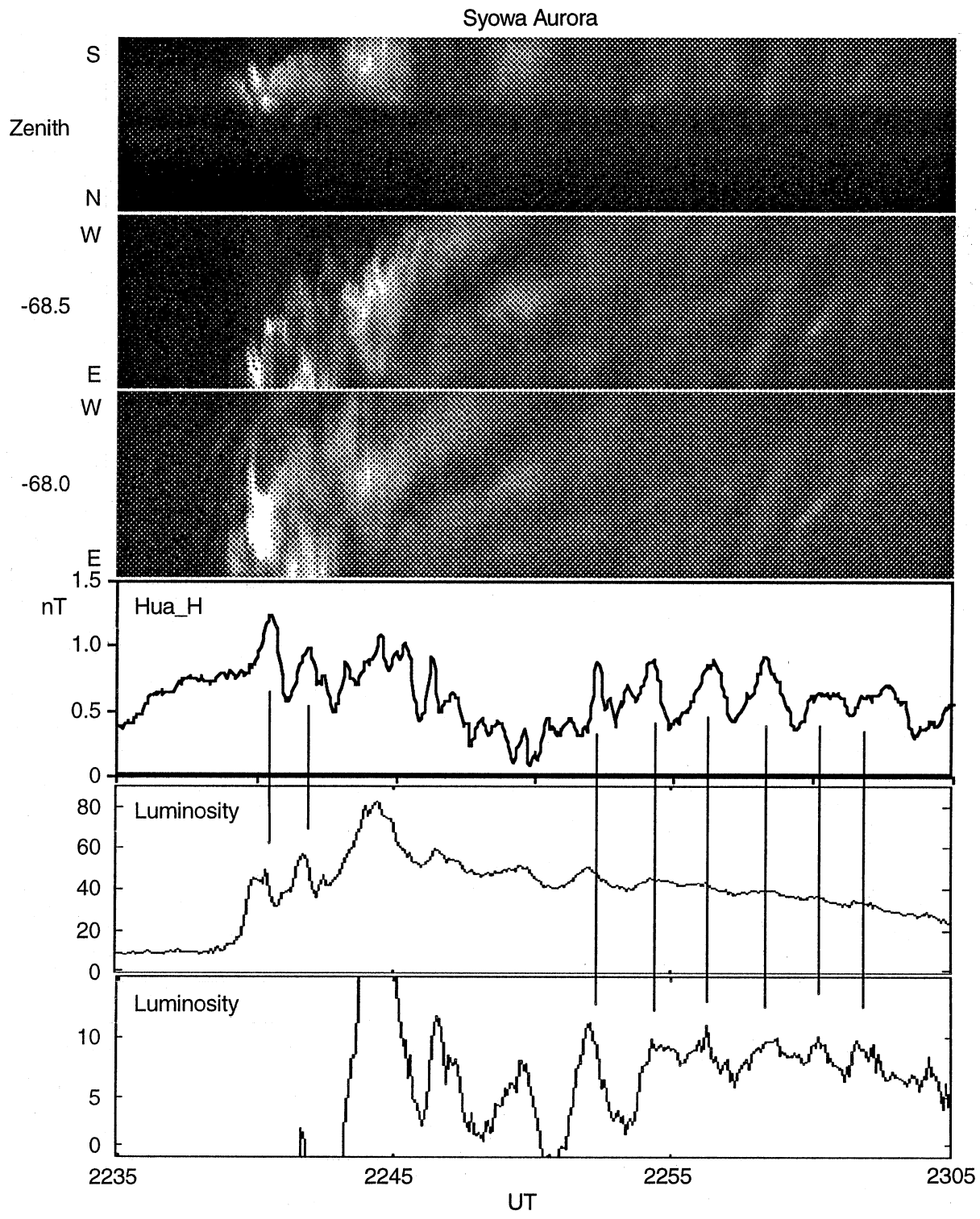

Fig. 2. Position-time display $(P-T$ display) of meridian scan (top panel), E-W scan (second and third panels) for the aurora event in Syowa field-of-view during the periods from 2235 to 2305 UT June 16, 1986. The line of the E-W scan is along geomagnetic latitudes $-68.5^{\circ}\left(-68.0^{\circ}\right)$ for second (third) panel. The luminosity was integrated over the E-W longitude crossing $-68.5^{\circ}$ to demonstrate the time variations. These are shown in the fifth and sixth panels. In the sixth panel, the background level was removed to emphasize the variations in the later periods. Fluxgate magnetometer data for the pulsation event recorded at Huancayo (dip-equator) is shown in the fourth panel. The vertical bars indicate the correspondence between the modulations of luminosity and Pi 2 wave form 

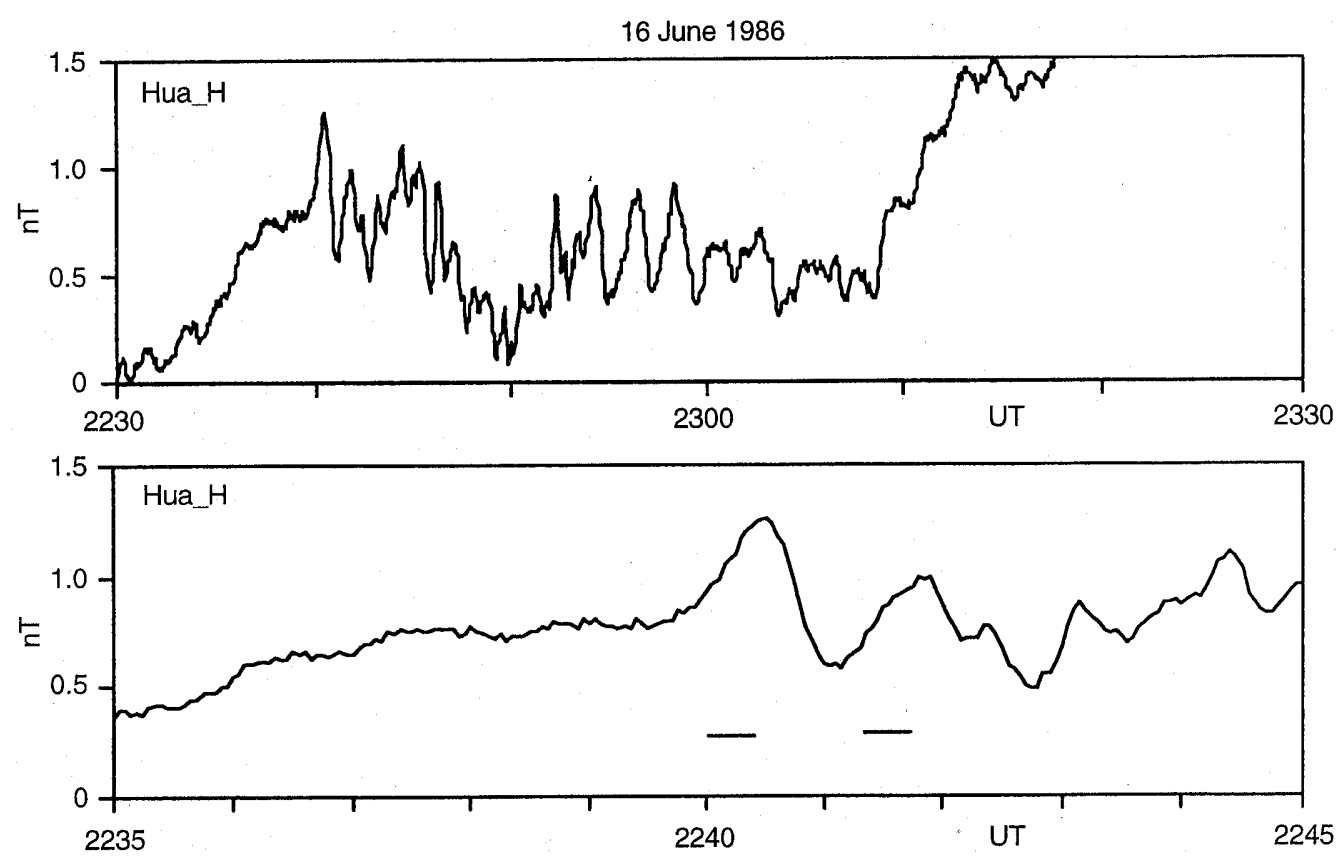

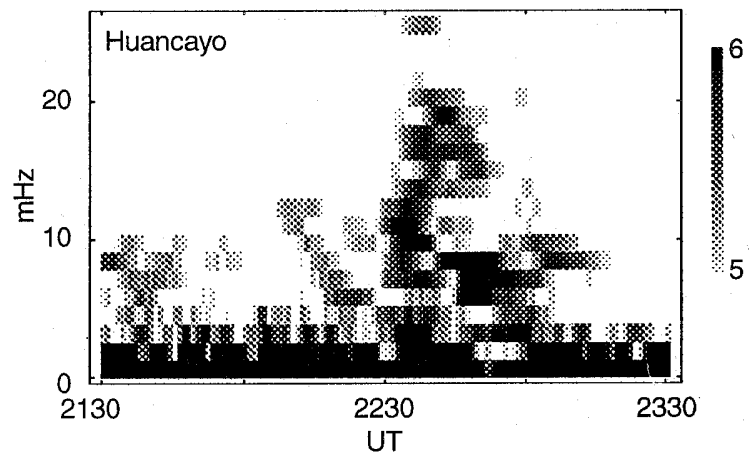

Fig. 3. Plot of the ground Pi 2 event that span 2230 to 2330 UT (upper panel). An enlarged portion of the onset of Pi 2 (2235-22245 UT) is shown in the second panel. In the bottom, dynamic power spectra of Huancayo and Kuju covering the Pi 2 event are depicted

UT. For the consecutive six cycles thereafter, the correspondences are clearly demonstrated in Fig. 2 as shown by vertical bars. In Fig. 6, all-sky images sampled every $12 \mathrm{~s}$ are presented during fourth and fifth cycle (2257:00 to $2300: 48$ UT). It shows that the first auroral patch (single arrow) appeared at the eastern edge of the FOV (upper left corner) at 2257:12 UT, then the luminosity of the patch increased as the patch moved westward (lower left corner). This patch died away at the western edge at 2259:12 UT. The maximum luminosity of the first patch was at 2258:12-2258:24 UT. The second patch (double arrow) appeared at the eastern edge at 2258:36 UT, then moved westward increasing its luminosity. This patch died away at 2300:24 UT. The maximum luminosity was seen at 2259:48-2300:00 UT. The variation of the integrated luminosity as shown in Fig. 2 is attributable to the temporal modulation of the luminosity for the auroral patches moving westward.

\section{Summary and discussion}

We have demonstrated concurrent oscillations/modulations of ground magnetometer signals at the dipequator and auroral precipitation in all-sky camera images. The observations were carried out from the afternoon to the midnight sector, at 1739 LT at Huancayo, and at 2239 LT in the all-sky image. Adding the observation at the low-latitude ground magnetometer station, $\mathrm{KUJ}(L=1.2)$ at $0739 \mathrm{LT}$, the event was observed to spread in the nightside sector to cover the region from dusk to dawn. Based on our statistical study of the initial response of the magnetic field lines at the geosynchronous altitudes at the Pi 2 onset (Saka et al., 1998a, b, c), we anticipate that the plasmas would have been supplied along the field lines from tailward plasma sheet, and filled the magnetic field lines right at the Pi 2 onset in broader longitudes in the nightside magnetosphere. These plasmas that 
All - sky image, Syowa station, 16 June 1986

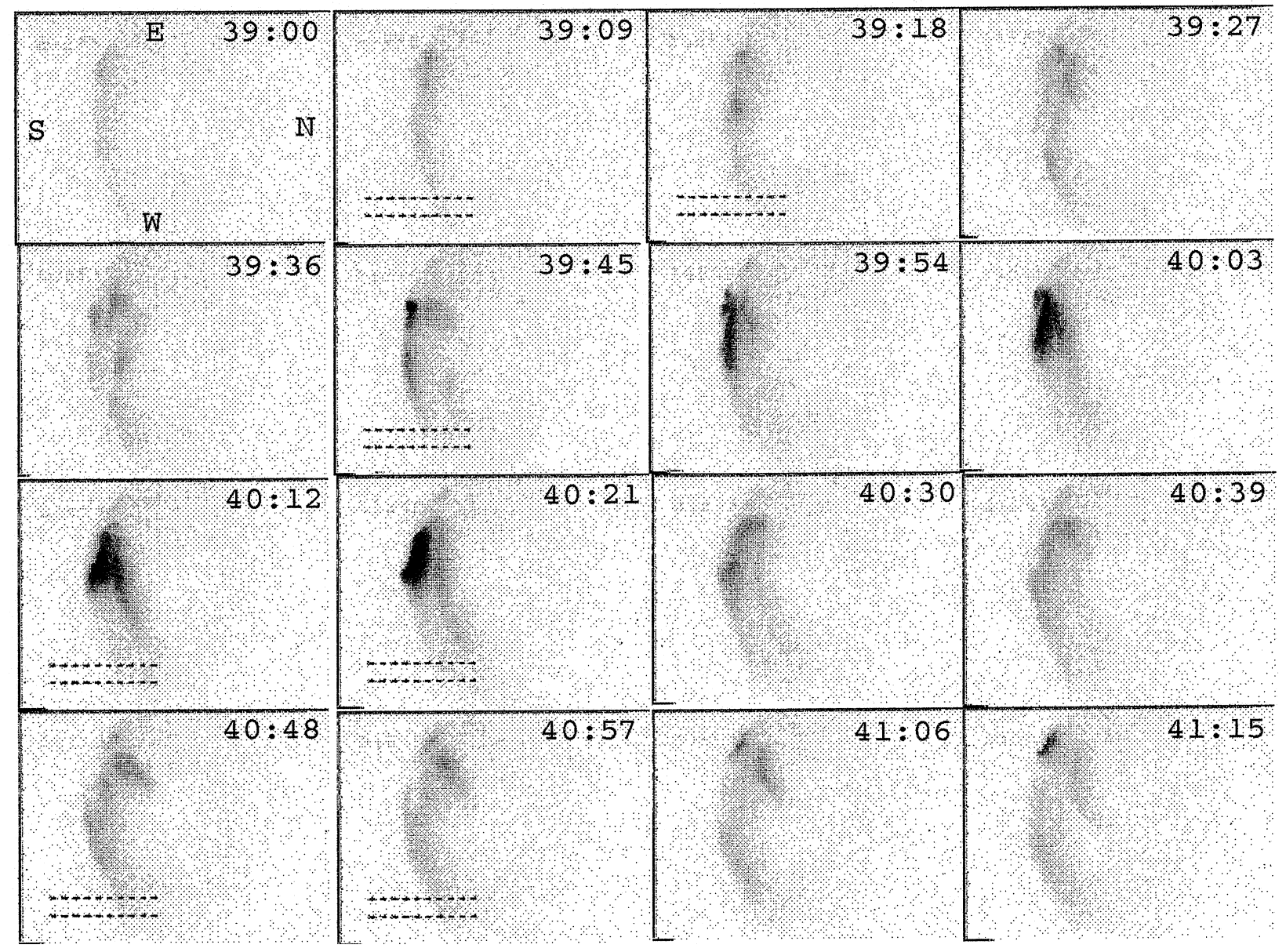

Fig. 4. All sky image at Syowa station. The image was sampled at $9 \mathrm{~s}$ during the auroral break-up covering the first maximum of the luminosity. The dots in some of the figures that appeared in the lower left portion are noises in the image. The aurora luminosity was

enhanced during the interval 2240:03-2240:21 UT. " $E$ " is for magnetic east, " $W$ " is for magnetic west, " $N$ " is for magnetic north, and " $S$ " is for magnetic south

All - sky image, Syowa station, 16 June 1986

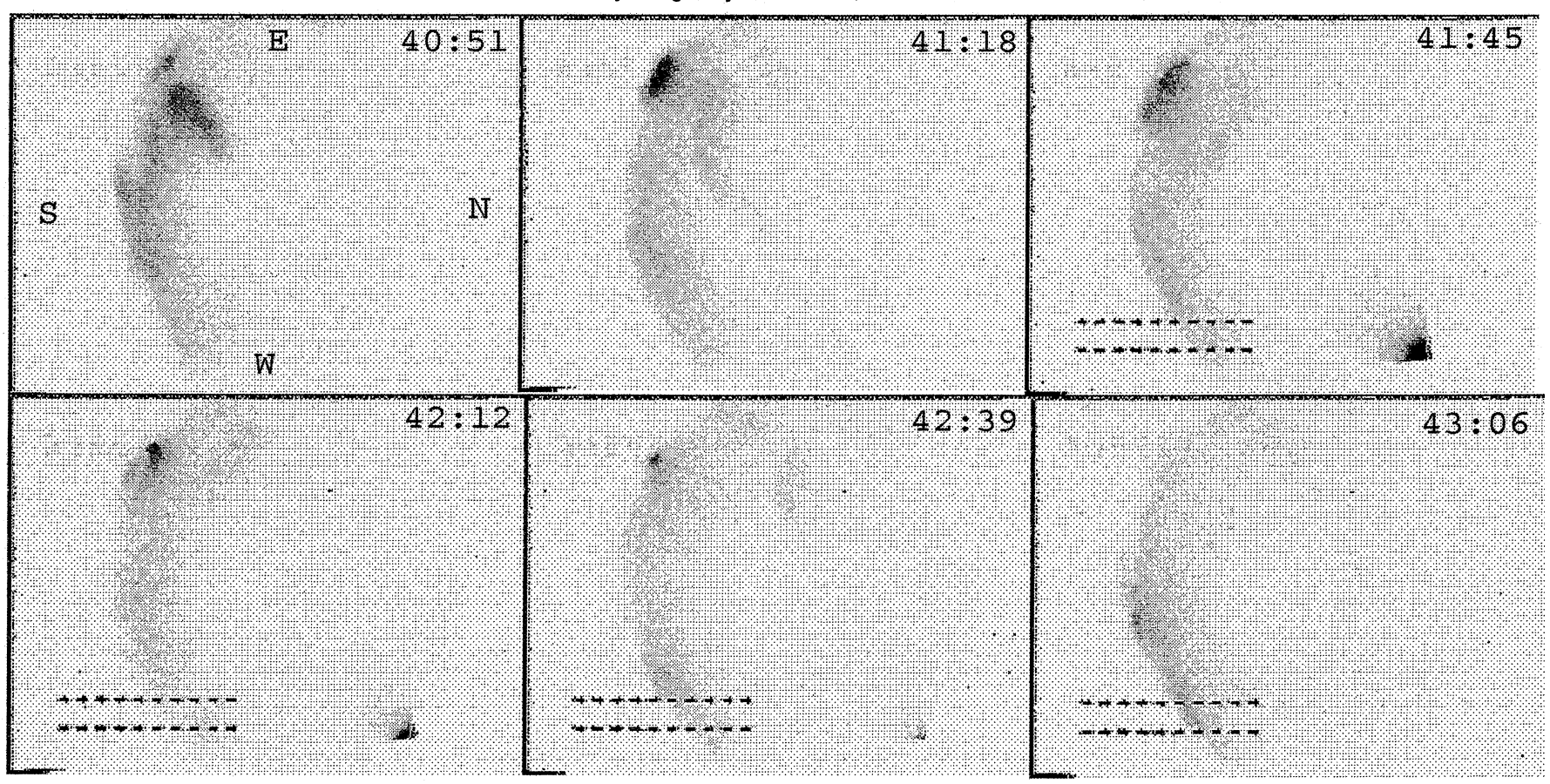




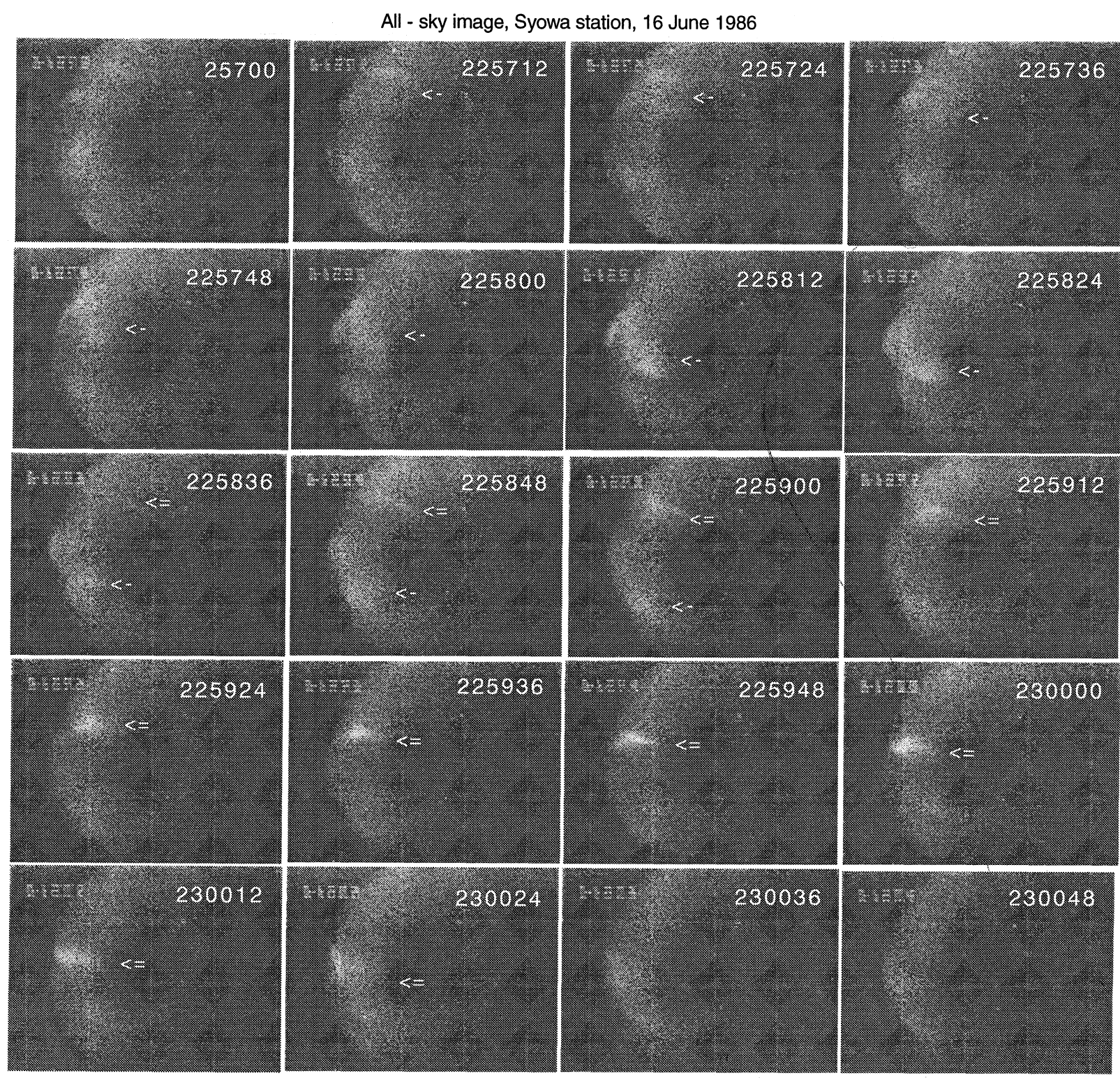

Fig. 6. Same as Fig. 4 but for the periodic interval, 2257:00 to 2300:48 UT. All-sky images are sampled at every $12 \mathrm{~s}$. A consecutive appearance of aurora patches as marked by the single and double arrows is demonstrated. They moved westwards increasing its luminosity and then died away (see text)

maintain the pressure balance at the earthward boundary of the plasmas. These diamagnetic currents divert into the field-aligned currents at the dawn and dusk sector. The field-aligned currents oscillate according to the field line resonance (Saka et al., 1996a, 1998b). It is apparent that the plasmas which once filled the field lines initiated the oscillation of the current intensity of the system which includes the eastward diamagnetic currents at the earthward boundary. We argue that cross-field part of the current system (i.e., diamagnetic currents) may launch the fast mode wave. This wave could be observed as a cavity mode at low latitude ground stations (Allan et al., 1996), while the fieldaligned part of the current system may launch the resonance mode as observed at high latitudes (Kuwashima, 1978).
Fig. 5. Same as Fig. 4 but for the second peak of the luminosity. The aurora luminosity was enhanced during the interval 2241:18-2241:45 UT 

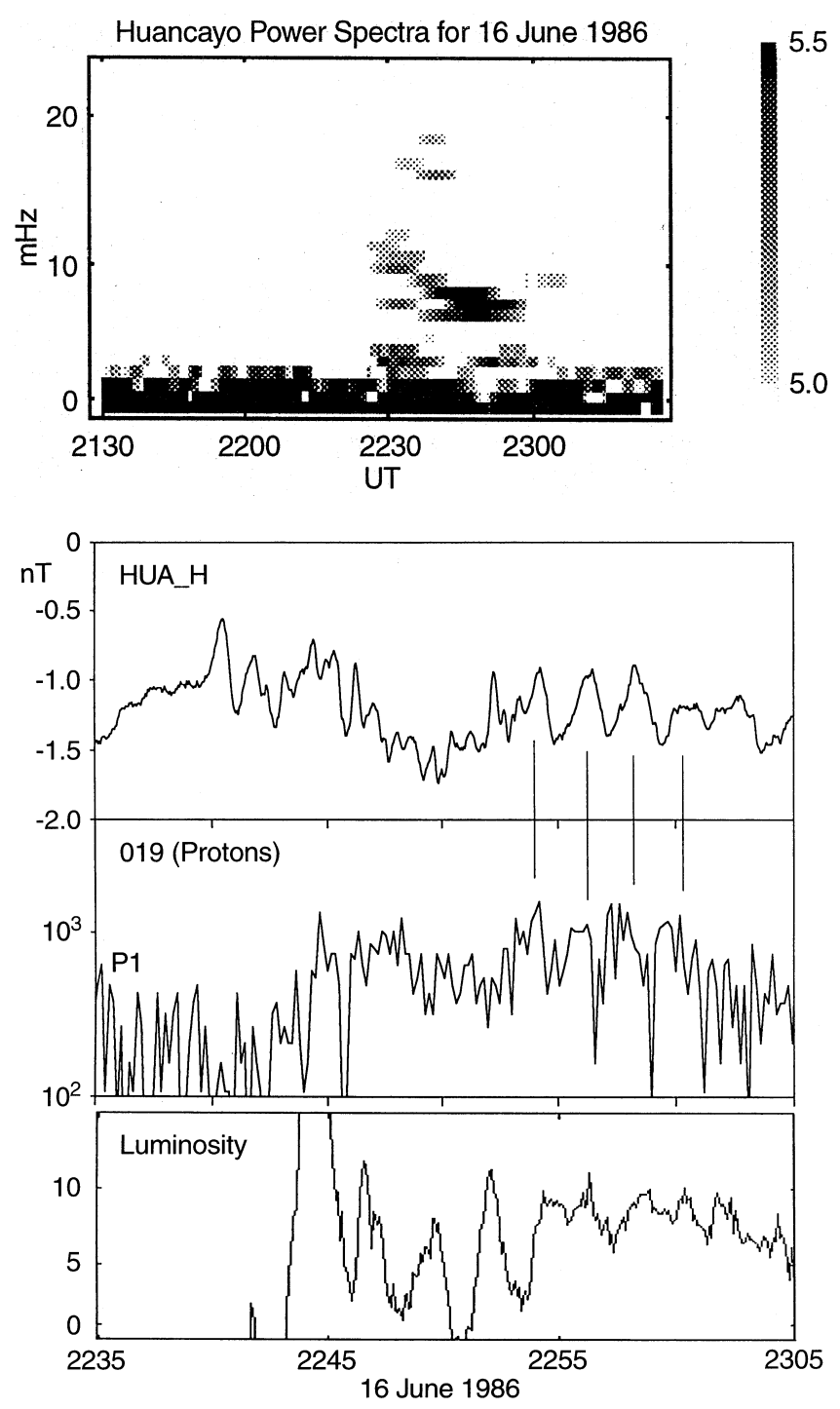

An important characteristic of the acceleration is that the particles taking part must be in lower energy ranges, probably below a few keV (e.g., Shepherd et al., 1980). It was argued that a lower part of the energy spectra $(<1 \mathrm{keV})$ probably responsible for the auroral precipitation may respond oppositely to the higher part of the energy, $>30 \mathrm{keV}$ for electrons and $>72 \mathrm{keV}$ for protons (Arnoldy, 1986; Saka et al., 1997). Such a correlation was examined for the present case by comparing ground $\mathrm{Pi} 2$ wave form, high energy proton flux in the geosynchronous altitudes, and the precipitation as observed by the auroral luminosity. The results are depicted in Fig. 7. The $H$ component on the ground increased while the high energy flux in the geosynchronous altitudes increased as was reported previously. The power spectral profiles shown at the top indicate a concurrent modulation at $8 \mathrm{mHz}$ band, wherein the ground signal lagged behind the flux modulation by about $60^{\circ}$ as estimated by the cross-spectrum analysis (not shown). It is evident that the precipitation was enhanced while the high energy flux increased at the

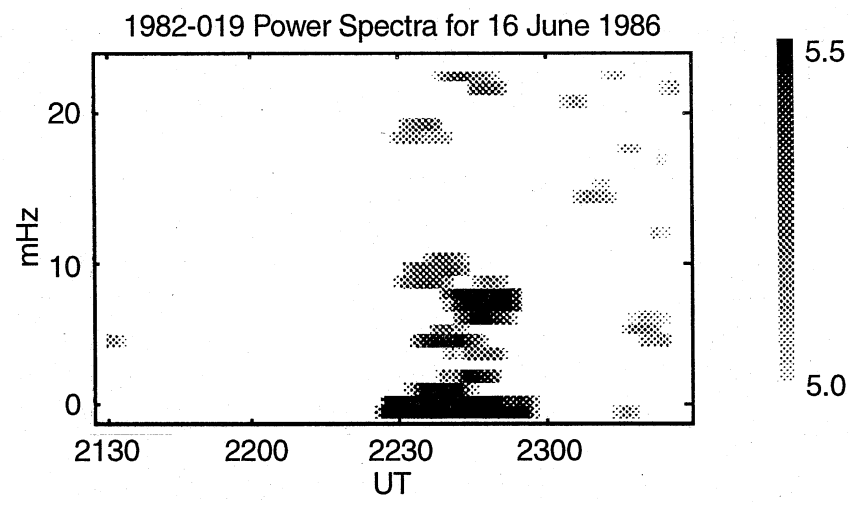

Fig. 7. Plot showing a possible correlation among ground $\mathrm{Pi} 2$ wave form, proton flux (P1; 95-110 keV) in the midnight sector (2011 LT), and integrated luminosity of the aurora. Profiles of the power spectra for the ground Pi 2 (left) and proton flux (right) are shown in the top (plotted in logarithmic arbitrary scale). Possible correspondences are marked by the vertical bars

geosynchronous altitudes. Such an opposite correlation was demonstrated first by Arnoldy (1986) for a Pi 2 event by use of particle data in wider energy range detected by ATS satellite. Although the Arnoldy result was interpreted as indicating heating and cooling of the Maxwellian distribution caused by the oscillation of the injection front, we argue that the Pi 2 modulation of the auroral precipitation as seen in the Syowa FOV would take place as a result of the modulation of the primary acceleration of the particles near the equator of the midnight magnetosphere.

Finally, we would like to suggest that a close association of the auroral image with the ground magnetometer observation reported in this study was not an unique case but can often be seen in the Huancayo-Syowa data set.

Acknowledgements. The aurora image at Syowa Station was supplied by WDC-C2 for Aurora, NIPR. DNB was supported by NASA. OW is supported by JSPS Research Fellowship for Young Scientist.

Topical Editor K.-H. Glassmeier thanks two referees for their help in evaluating this paper. 


\section{References}

Allan, W., F. W. Menk, B. J. Fraser, Y. Li, and S. P. White, Are low-latitude Pi 2 pulsations cavity/waveguide modes?, Geophys. Res. Lett., 23, 765, 1996.

Akasofu, S.-I., The development of the auroral substorm, Planet, Space Sci., 12, 273, 1964.

Arnoldy, R. L., Fine structure and pitch angle dependence of synchronous orbit electron injections, J. Geophys. Res., 91, 13411, 1986.

Burch, J. L., Diagnosis of auroral acceleration mechanisms by particle measurements, in Auroral Physics, Eds. C-I. Meng, M. J. Rycroft, and L. A. Frank, Cambridge University Press, 1991.

Jacobs, J. A., Geomagnetic micropulsations, Springer, New York Berlin Heidelberg, 1970.

Kuwashima, M., Wave characteristics of magnetic Pi2 pulsations in the high latitude region, spectral and polarization studies, Mem. Natl. Inst. Polar Res., Spec. Issue Ser. A. 15, 79, 1978.

Nakamura, R., and T. Oguti, Drifts of auroral structures and magnetospheric electric field, J. Geophys. Res., 92, 11241, 1987.

Saito, T., Geomagnetic micropulsations, Space Sci. Rev., 10, 319, 1969.

Saka, O., O. Watanabe, M. Shinohara, H. Tachihara, and D. N. Baker, A comparison of the occurrence of very-low-latitude Pi 2 pulsations with magnetic-field and energetic-particle flux variations (30-300 keV) at geosynchronous altitudes, J. Geomag, Geoelectr., 48, 1431, 1996 a.

Saka, O., H. Akaki, O. Watanabe, and D. N. Baker, Groundsatellite correlation of low-latitude Pi2 pulsations: a quasi- periodic field line oscillation in the magnetosphere, J. Geophys. Res., 101, 15 433, 1996b.

Saka, O., O. Watanabe, and D. N. Baker, A possible driving source for transient field line oscillations in the postmidnight sector at geosynchronous altitudes, J. Geophys, Res., 101, 24 719, 1996c.

Saka, O., K. Okada, O. Watanabe, and D. N. Baker, Pi 2associated particle flux and magnetic field modulations in geosynchronous altitudes, J. Geophys. Res., 102, 11 363, 1997.

Saka, O., H. Akaki, O. Watanabe, M. Shinohara, and D. N. Baker, An initial response of magnetic fields at geosynchronous orbit to Pi 2 onset as observed from the dip-equator, 16, 542, Ann. Geophysicae, 1998a.

Saka, O., H. Akaki, O. Watanabe, M. Shinohara, K. Okada, and D. N. Baker, Possible plasma dynamics in nighttime magnetosphere associated with Pi 2 onset as observed from dip-equator, Proc. NIPR Symp. Upper Atmos. Phys., 12, 162, 1998b.

Saka, O., O. Watanabe, M. Shinohara, H. Akaki, and D. N. Baker, Possible plasma dynamics in nighttime magnetosphere during first one-minute-interval of the Pi 2 onset, Proc. International Conference on Substorms-4, 559; 1998c.

Shepherd, G. G., R. Bostron, H. Derblom, C.-G. Falthammar, R. Gendrin, K. Kaila, A. Korth, A. Pedersen, R. Pellinen, and G. Wrenn, Plasma and field signatures of poleward propagating auroral precipitation observed at the foot of the Geos 2 field line, J. Geophys. Res., 85, 4587, 1980.

Tsyganenko, N. A., Tsyganenko 1989 model and related software (GEOPACK), NSSDC Data set MG-25c, 1991. 